\title{
Placental Maspin Gene Expression Pattern May Be Used to Distinguish Between Preeclampsia and Intrauterine Growth Restriction
}

\author{
Gogsen ONALAN ${ }^{*}$, Yunus Kasim TERZI², Yusuf Aytac TOHMA¹, Erkan YURTCU³ , Esra KUSCU', \\ Feride Iffet SAHIN², Hulusi Bulent ZEYNELOGLU1
}

Ankara, Turkey

\begin{abstract}
OBJECTIVE: Maspin is one of the members of serin protease inhibitor superfamily, and acts as a tumor suppressor protein. Here we report maspin expression in placental tissues of preeclampsia or intrauterine growth retardation pregnancies.
\end{abstract}

STUDY DESIGN: Maspin expression level was analyzed by semi-quantitative RT-PCR method. For this purpose, placental tissue samples were obtained from pregnancies 13 with intrauterine growth retardation, and 6 with preeclampsia, and also 12 tissues from women without preeclampsia or intrauterine growth retardation history were included as controls.

RESULTS: Maspin expression was found to be 11-fold higher in placentas from preeclampsia patients than placentas from intrauterine growth retardation patients $(p=0.036)$. However, there was no difference between preeclampsia and control groups $(p=0.76)$, and intrauterine growth retardation and control groups $(p=0.849)$.

CONCLUSION: As far as we know this is the first study reporting expression level of maspin in placental tissues of pregnancies with intrauterine growth retardation. These findings support that molecular pathology between preeclampsia and IUGR might be different at the molecular level and maspin levels in the placenta may be used to differentiate preeclampsia from IUGR.

Keywords: Intrauterine growth restriction, Maspin, Preeclampsia, Pregnancy

Gynecol Obstet Reprod Med 2021;27(2):99-104

${ }^{I}$ Department of Obstetrics and Gynecology, Baskent University Faculty of Medicine, Ankara, Turkey

2 Department of Medical Genetics, Baskent University Faculty of Medicine, Ankara, Turkey

${ }^{3}$ Department of Medical Biology, Baskent University Faculty of Medicine, Ankara, Turkey

Address of Correspondence: Gogsen Onalan

Baskent University Faculty of Medicine, Department of Obstetrics and Gynecology Sehit H. Temel Kuguluoglu Sok. No 32,

Bahcelievler, Ankara, 06490 Turkey

gogsenonalan@yahoo.com

Submitted for Publication: 03.05.2019 Revised for Publication: 09.08.2019 Accepted for Publication: 22.09.2019 Online Published: 02.08.2021

ORCID IDs of the authors:

YKT: 0000-0001-5612-9696 EY: 0000-0003-4930-8164

GO: 0000-0003-3446-3751

YAT: 0000-0001-9418-4733

EK:0000-0002-3822-2552

FIS: 0000-0001-7308-9673

\begin{tabular}{c|c}
\hline Quick Response Code: & Access this article online \\
\cline { 2 - 2 } & $\begin{array}{c}\text { Website: www.gorm.com.tr } \\
\text { e- mail: info@gorm.com.tr }\end{array}$ \\
\cline { 2 - 2 } & DOI:10.21613/GORM.2019.969 \\
\hline
\end{tabular}

How to cite this article: Onalan G. Terzi YK. Tohma YA. Yurtcu E. Kuscu E. Sahin FI. Zeyneloğlu HB. Placental Maspin Gene Expression Pattern May Be Used to Distinguish Between Preeclampsia and Intrauterine Growth Restriction. Gynecol Obstet Reprod Med 2021;27(2):99-104

\section{Introduction}

Intrauterine growth restriction (IUGR) points to a situation in which a fetus cannot reach the genetically determined potential size (1). It has been reported that IUGR is observed nearly $7-10 \%$ of all pregnancies and it found to be related with increased risk of neonatal morbidity and mortality $(2,3)$. While IUGR affects the fetus, preeclampsia which is characterized by the onset of hypertension and proteinuria in previously normotensive women after the $20^{\text {th }}$ gestational weeks affects pregnant women and fetus and observed $5-8 \%$ of all pregnancies $(4,5)$.

Preeclampsia and IUGR are disorders that are associated with defects of early placental development (6). The placenta is a very complex structure and contains many types of cells include connective tissue fibroblasts, vascular cells, mesenchymal stem cells, syncytiotrophoblast, villous/extravillous cytotrophoblast, and extravillous cytotrophoblast cell is one of the main cell types of the placenta (7). During the development of placenta and embryo, it is expected that extravillous cytotrophoblast cells moving to endometrium and myometrium, and the endothelial layer of mater-nal spiral arteries is replaced with extravillous cytotrophoblasts cells $(8,9)$. 
Decreasing invasion rate of extravillous cytotrophoblast cells during this period might be the underlying reason for the development of preeclampsia and IUGR (5).

Mammary serine protease inhibitor (maspin) is a serine protease inhibitor and acts as a tumor suppressor gene which affects tumor cells and reduces invasion, metastasis, and angiogenesis $(10,11)$. It also has been identified in human placentas, differentially expressed throughout gestation in accordance with cytotrophoblast invasion during implantation, early placental development, downregulated and later in gestation up-regulated. Thus, Maspin is considered as an inhibitory regulator of cytotrophoblastic invasion during pregnancy (12). Based on these findings, in this study, we aimed to detect the maspin expression in preeclamptic and intrauterine growth restriction placentas and to understand the role of maspin expression in the development of preeclampsia and IUGR.

\section{Material and Method}

A prospective and controlled study was performed at Baskent University Faculty of Medicine, Ankara, Turkey; 13 patients with IUGR, 6 patients with preeclampsia, and 12 control individuals were included in the study. The diagnostic criteria used for the preeclampsia patients were as follows: newonset hypertension, blood pressure $\geq 140 / 90 \mathrm{~mm} \mathrm{Hg}$ on at least two measurements that were 4 hours to 1 week apart, and proteinuria $>300 \mathrm{mg}$ in a 24-hour urine collection after 20 weeks of gestation. The diagnostic criteria used for the IUGR patients were as follows: birth weight $\leq 10^{\text {th }}$ percentile and antenatal evidence of uteroplacental insufficiencies such as oligohydramnios, abnormalities in the biophysical profile, nonstress testing, or umbilical artery Doppler waveform. The placental tissues were obtained immediately following delivery from patients with singleton pregnancies complicated with preeclampsia, IUGR, and uncomplicated pregnancies. Patients who had gestational diabetes mellitus, intrapartum infection, chronic hypertension, renal disease and premature rupture of membranes, were excluded from this study. Informed consent was obtained from all patients and controls. The Local ethical committee approved this study (DA08/19). This study was performed in accordance with the principles of the Declaration of Helsinki.

\section{Sample collection}

Fresh placentas samples which were obtained from the central region of the placenta immediately after extraction from the uterus were trimmed to $1 \times 1 \mathrm{~cm}$ (mean surface area equal to $1 \mathrm{~cm}^{2}$ ) along the placental thickness from the basal toward the chorionic surface. Firstly, maternal blood was excluded by vigorous washing in phosphate-buffered saline and then some samples were fixed in $4 \%$ paraformaldehyde and others were immediately cryopreserved with liquid nitrogen and stored at $-70{ }^{\circ} \mathrm{C}$.

\section{Genetic Analysis}

Total RNA was extracted from placental villi of IUGR, preeclampsia patients, and controls with TriPure isolation reagent according to the manufacturer's instructions (Roche Diagnostics GmbH, Mannheim, Germany). One microgram of total RNA was reverse transcribed to complementary DNA using the Transcriptor First-Strand cDNA Synthesis Kit (Roche Diagnostics, GmbH, Mann-heim, Germany). The expression level of Maspin was determined using LightCycler FastStart DNA Master ${ }^{\text {PLUS }}$ SYBR Green I Kit (Roche Diagnostics, GmbH, Mannheim, Germany). PCR parameters were as follows: pre-incubation step at $95{ }^{\circ} \mathrm{C}$ for 10 minutes, quantification step for 45 cycles at $95^{\circ} \mathrm{C}$ for 10 seconds, $60{ }^{\circ} \mathrm{C}$ for 10 seconds, and $72{ }^{\circ} \mathrm{C}$ for 10 seconds. Following the amplification, melting curve analysis was performed. TATA-box binding protein (TBP) was used as a housekeeping gene. Relative gene expression data were analyzed using the 2 (-Delta Delta C (T)) method (13). Primer sequences of the target genes are listed in table I.

\section{Statistical analysis}

SPSS Statistical 17 package (SPSS Inc., IL, Chicago, USA) program was used for statistical analysis of the data. Significant differences between groups were determined using independent samples $t$-test. A $p$-value of less than 0.05 was considered statistically significant.

\section{Results}

We studied 31 pregnant patients (13 IUGR, 6 preeclampsia, and 12 control individuals) and clinical characteristics of patients were presented in table II. There was no statistical significance between clinical characteristics and groups. The mean maternal age was $26.5 \pm 4.91,27.2 \pm 4.29$ and $28.2 \pm 4.02$ years in preeclampsia, IUGR, and control groups. The mean gestational age at delivery was $32.4 \pm 1.4$ weeks for preeclamptic patients, $35.38 \pm 1.2$ weeks for IUGR patients and 37.6 \pm 0.6 weeks for control patients. The mean birth weight was 1782.8 $\pm 601.5,1564.1 \pm 711.1$ and $2975.3 \pm 639.2$ in preeclampsia, IUGR and control groups.

Table I: Primers used for real-time polymerase chain reaction analysis.

\begin{tabular}{lll}
\hline Gene & Forward primers $\left(5^{\prime}\right.$ to $\left.3^{\prime}\right)$ & Reverse primers $\left(5^{\prime}\right.$ to $\left.3^{\prime}\right)$ \\
Maspin & GTCCACAGGCTTGGAGAAG & ACAAGCCTTGGGATCAATCA \\
TBP* $^{*}$ & CACGAACCACGGCACTGATT & ATTTTCTTGCTGCCAGTCTGGAC
\end{tabular}


Table II: Clinical details of the pregnant women with preeclampsia, IUGR, and the matched nor-mal control group

\begin{tabular}{lccc}
\hline & Control $(\mathrm{n}=12)$ & $\mathrm{PE}(\mathrm{n}=6)$ & IUGR $(\mathrm{n}=13)$ \\
\hline Maternal Age (years) & $28.2 \pm 4.02$ & $26.5 \pm 4.91$ & $27.2 \pm 4.29$ \\
BMI at delivery $\left(\mathrm{kg} / \mathrm{m}^{2}\right)$ & $26.3 \pm 1.7$ & $28.4 \pm 1.2$ & $27.3 \pm 0.9$ \\
Gravidity (median, range) & $2(1-4)$ & $1(1-3)$ & $1(1-3)$ \\
Primiparity, $\mathrm{n}(\%)$ & $8(66 \%)$ & $4(66 \%)$ & $8(62 \%)$ \\
Cigarettes & 2 & 1 & 3 \\
GA at delivery (wk) & $37.6 \pm 0.6$ & $32.4 \pm 1.4$ & $35.38 \pm 1.2$ \\
SBP (mm Hg) & $107.0 \pm 1.8$ & $154.2 \pm 2.4$ & $104.7 \pm 1.9$ \\
DBP (mm Hg) & $69 \pm 1.5$ & $101 \pm 3.8$ & $72 \pm 1.7$ \\
Proteinuria (g/24 h) & $0.28 \pm 0.41$ & $2.1 \pm 1.41$ & $0.39 \pm 1.56$ \\
Antenatal steroids & 0 & 6 & 8 \\
Magnesium sulfate & 0 & 6 & 0 \\
Neonatal Male/female & $5 / 7$ & $3 / 3$ & $5 / 8$ \\
Birth Weight (g) & $2975.3 \pm 639.2$ & $1782.8 \pm 601.5$ & $1564.6 \pm 711.1$ \\
Apgar 5 min & $8.8 \pm 0.4$ & $7.7 \pm 0.5$ & $5.9 \pm 0.9$
\end{tabular}

BMI: Body mass index; GA: Gestational age; SBP: Systolic blood pressure; DBP: Diastolic blood pressure; IUGR: Intrauterine growth restriction. The values are presented as means $\pm S D$ s. / all $p$ values $>0.05$

Semi-quantitative RT-PCR analysis revealed that there was a statistically significant difference between the placentas from preeclampsia and IUGR patients in terms of maspin expression (placentas from preeclampsia patients was 11-fold higher than placentas from IUGR patients) $(p=0.036)$ (Figure 1). However, there was not a statistically significant difference of Maspin expression between preeclampsia vs control groups $(p=0.76)$, and IUGR vs control groups $(p=0.849)$.

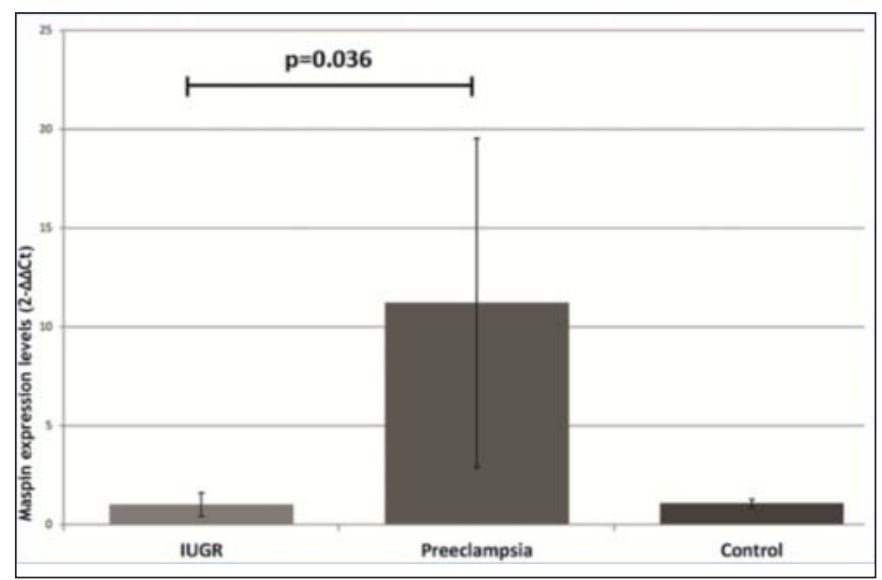

Figure 1: $q R T-P C R$ analysis of Maspin in the placentas from pregnancies with IUGR, preeclampsia and the control groups. Maspin expression in placentas from preeclampsia patients was 11-fold higher than placentas from IUGR patients ( $p=$ 0.036). (IUGR: Intrauterine Growth Restriction, qRT-PCR: quantitative Real Time-Polymerase Chain Reaction)

\section{Discussion}

Maspin is considered a tumor suppressor gene because it has inhibitory effects on the motility, invasion, and metastasis of several cancer cells (11). Hypomethylation of Maspin has been shown to be related to inhibition of cytotrophoblastic invasion during pregnancy. Therefore, we aimed to ana-lyze
Maspin expression in placentas from preeclampsia and IUGR pregnancies. To the best of our knowledge, this is the first study to evaluate Maspin expression in placentas from IUGR pregnancies and compare Maspin expression in placentas from preeclampsia and IUGR pregnancies. In this study, firstly, although we observed that there was not a statistically significant difference of Maspin expression between IUGR vs control groups $(p=0.849)$, these were the first data about the association between IUGR and maspin expression in placentas. Secondly and interestingly, the qRT-PCR analysis revealed that Maspin expression in placentas from preeclampsia patients was 11-fold higher than placentas from IUGR patients and there was a statistically significant $(p=0.036)$.

Placental trophoblast cell differentiation and invasion of extravillous cytotrophoblast cells to endometrium and myometrium and replacing with an endothelial layer of the maternal spiral arteries are necessary for the formation of the normal placenta and significant changes in gene expression pattern were detected during this stage $(4,14,15)$. Dysregulation of these gene expression patterns and consequent any abnormality during placenta formation may cause preeclampsia that is the primary cause of maternal and perinatal morbidity and mortality worldwide $(4,11)$. Therefore, the epigenetic mechanism was found to be important in the development of preeclampsia (16-18). Currently, a number of genes such as cytokine-receptor genes, obesity-related genes, and apoptosisrelated genes have been identified related to the development of preeclampsia (18).

Maspin which is a tumor suppressor gene and inhibits invasion, motility, and metastasis of tumor cells and neoangiogenesis, is one of these genes (11). Maspin expression was downregulated via promoter methylation and this effect were studied previously in different cancer type $(19,20)$. It has been 
also reported that maternal plasma concentrations of unmethylated maspin sequences were found to be higher in 5.7fold in preeclamptic pregnancies that have dysfunction of trophoblast in-vasion and reduced neoangiogenesis of the placenta, compared to healthy pregnancy controls (21). Additionally, Liu et al. (10) showed that maspin was localized in the syncytio-cytotrophoblast layers, and its expression was found to be increased in the preeclamptic placenta section compared to the matched control. Our finding supports the previous literature that maspin expression was found to be increased in placentas from preeclampsia group.

Both preeclampsia and normotensive IUGR are associated with decreased invasion of extravillous cytotrophoblast cells causing to incomplete replacing with an endothelial layer of the maternal spiral arteries (22). However, in the literature, differences are shown in the placenta of preeclampsia and normotensive IUGR $(23,24)$. Goswami et al. (25) showed that placentas in early-onset preeclampsia have more necrosis and syncytial knots area that are clusters of pre-apoptotic/apoptotic nuclei than placentas in normotensive IUGR. Lorenzi et al. investigated the expression of a different form of HighTemperature Requirement A Serine Peptidase 1 (HtrA1) in placentas from preeclampsia and IUGR. (26). HtrA1 which is a member of the family of HtrA proteins has serine protease activity. They observed that a significant increase of $\sim 30 \mathrm{kDa}$ form of HtrA1 in placentas from preeclampsia and a significant decrease in the total in placentas from IUGR. As a result of this, they suggested that HtrA1 alterations may be used to differentiate preeclampsia from IUGR. In our study, on the contrary to the preeclampsia group, IUGR group have similar maspin expression level with the control group. The final net result between those contrast mechanisms may increase in maspin level and it could be suggested that proteins have serine protease activity (HtrA1) and inhibitor effects on serine protease (maspin) are essential for normal placental development and expression of these proteins are different between placentas from preeclampsia and IUGR. Therefore, we speculated that maspin levels in the placenta may be used to differentiate preeclampsia from IUGR.

Serine protease inhibitors (SERPINs) which regulate many biological processes such as inflammation, wound healing and coagulation, are a superfamily containing at least 37 proteins (27). SERPINs play a role in the pathology of various diseases such as Parkinson's disease, cystic fibrosis, cerebral hemorrhage, stroke, and Alzheimer's disease (27). Additionally, recently, it has been shown that SERPINs can also play a role in placental diseases $(28,29)$. In the study of Chelbi et al. (27), they showed that $\mathrm{T}$ allele of SERPINA3 (Serpin peptidase inhibitor clade A member 3) increases the risk of IUGR, while a $\mathrm{G}$ allele increases the risk of preeclampsia. As a result of this, they said that the regulation of SERPINA3 by a combination of epigenetic, genetic and TF-mediated regulations is important for the pathogenesis of different placental diseases.
In our study, we aimed to analyze Maspin (encoded by SERPINB5) in placentas from preeclampsia and IUGR pregnancies and we revealed that Maspin expression in placentas from preeclampsia patients was 11-fold higher than placentas from IUGR patients. Therefore, we speculated that the regulation of SERPINB5 (maspin) may be important for the pathogenesis of different placental diseases.

The present study has some limitations include the number of patients in the preeclampsia group is almost half of the other groups and cigarette smoking which may affect results did not exclude. Additionally, we observed that higher maspin expressions in the preeclampsia group than the control group; however, there was no statistically significant difference between them different from literature (18), and we assume that the reason for this might be the small patient population. Additional well-designed, large-scale studies are required to improve our understanding of associations be-tween maspin expression and pregnancy complications associated with placental insufficiencies such as IUGR and preeclampsia.

\section{Conclusion}

This finding suggests that molecular pathology between preeclampsia and IUGR might be different at the molecular level and maspin levels in the placenta may be used to differentiate preeclampsia from IUGR. However, wider gene sets should be analyzed to unravel the molecular difference between preeclampsia and IUGR.

\section{Acknowledgment: None}

Author contributions: Study concept and design: GO, YKT, Writing Manuscript: GO, YAT, Acquisition of data: YKT, FIS, EY, Analysis and interpretation of data: YAT, HBZ, GO, Drafting of the manuscript: YAT, HBZ, GO, EK, Critical revision of the manuscript for important intellectual content: $G O$, YAT, HBZ, FIS, EK, EY, YKT, Statistical analysis: YKT.

Conflict of Interest Statement: The authors of this paper have no conflicts of interest, including specific financial interests, relationships, and/or affiliations relevant to the subject matter or materi-als included.

Funding: This study was approved by Baskent University Institutional Review Board (Project no: DA08/19), and supported by Baskent University Research Fund.

\section{References}

1. Brar HS, Rutherford SE. Classification of intrauterine growth retardation. Semin Perinatol. 1988;12(1):2-10. PMID: 3287628.

2. Pollack RN, Divon MY. Intrauterine growth retardation: definition, classification, and etiology. Clin Obstet Gynecol. 1992;35(1):99-107. doi:10.1097/00003081-199 203000-00015.

3. Gray PH, O'Callaghan MJ, Harvey JM, Burke CJ, Payton DJ. Placental pathology and neurodevelopment of the in- 
fant with intrauterine growth restriction. Dev Med Child Neurol. 1999;41(1):16-20. doi: 10.1017/s0012162299000 043.

4. Lain KY, Roberts JM. Contemporary concepts of the pathogenesis and management of preeclampsia. JAMA. 2002;287(24):3183-6. doi: 10.1001/jama.287.24.3183.

5. Bahr BL, Price MD, Merrill D, Mejia C, Call L, Bearss D, et al. Different expression of placental pyruvate kinase in normal, preeclamptic and intrauterine growth restriction pregnancies. Placenta. 2014;35(11):883-90. doi: 10.1016/ j.placenta.2014.09.005.

6. Ilekis JV, Tsilou E, Fisher S, Abrahams VM, Soares MJ, Cross JC, et al. Placental origins of adverse pregnancy outcomes: potential molecular targets: an Executive Workshop Summary of the Eunice Kennedy Shriver National Institute of Child Health and Human Development. Am J Obstet Gynecol. 2016;215(1 Suppl): S1-S46. doi: 10.1016/j.ajog.2016.03.001.

7. Telang MA, Bhutkar SP, Hirwani RR. Analysis of patents on preeclampsia detection and diagnosis: a perspective. Placenta. 2013;34(1):2-8. doi: 10.1016/j.placenta.2012. 10.017 .

8. Redman CW, Sargent IL. Latest advances in understanding preeclampsia. Science. 2005;308(5728):1592-4. doi: 10.1126/science. 1111726 .

9. Geusens N, Verlohren S, Luyten C, Taube M, Hering L, Vercruysse L, et al. Endovascular trophoblast invasion, spiral artery remodelling and uteroplacental haemodynamics in a transgenic rat model of pre-eclampsia. Placenta. 2008;29(7):614-23. doi:10.1016/j.placenta. 2008.04.005.

10. Liu Q, Qiao FY, Shi XW, Liu HY, Gong X, Wu YY. Promoter hypomethylation and increased maspin expression in preeclamptic placentas in a Chinese population. Placenta. 2014;35(11):876-82. doi:10.1016/j.placenta. 20 14.08.088.

11. Zhang Y, Liu H, Shi X, Qiao F, Zeng W, Feng L, et al. Maspin impairs the function of endothelial cells: an implying pathway of preeclampsia. BMC Pregnancy Childbirth. 2017;17(1):328. doi: 10.1186/s12884-017-15 25-z.

12. Li HW, Leung SW, Cheung AN, Yu MM, Chan LK, Wong YF. Expression of maspin in gestational trophoblastic disease. Gynecol Oncol. 2006;101(1):76-81. doi: 10.1016/j.ygyno.2005.09.037.

13. Livak KJ, Schmittgen TD. Analysis of relative gene expression data using real-time quantitative PCR and the 2 (-Delta Delta C(T)) Method. Methods. 2001;25(4):402-8. doi: 10.1006/meth.2001.1262.

14. Christians JK, Leavey K, Cox BJ. Associations between imprinted gene expression in the placenta, human fetal growth and preeclampsia. Biol Lett. 2017;13(11). doi: 10. 1098/rsbl.2017.0643.
15. Jiang SW, Zhou W, Wang J, Little LM, Leaphart L, Jay J, et al. Gene expression patterns associated with human placental trophoblast differentiation. Clin Chim Acta. 2019;495:637-45. doi: 10.1016/j.cca.2018.01.012.

16. Reimer T, Koczan D, Gerber B, Richter D, Thiesen HJ, Friese K. Microarray analysis of differentially expressed genes in placental tissue of pre-eclampsia: up-regulation of obesity-related genes. Mol Hum Reprod. 2002;8 (7):674-80. doi: 10.1093/molehr/8.7.674.

17. Tsoi SC, Cale JM, Bird IM, Kay HH. cDNA microarray analysis of gene expression profiles in human placenta: up-regulation of the transcript encoding muscle subunit of glycogen phosphorylase in preeclampsia. J Soc Gynecol Investig. 2003;10(8):496-502. doi: 10.1016/s1071-5576 (03) 00154-0.

18. Pang ZJ, Xing FQ. DNA microarrays detect the expression of apoptosis-related genes in preeclamptic placentas. J Perinat Med. 2004;32(1):25-30. doi:10.1515/JPM. 2004. 004.

19. Helal DS, El-Guindy DM. Maspin expression and subcellular localization in invasive ductal carcinoma of the breast: Prognostic significance and relation to microvessel density. J Egypt Natl Canc Inst. 2017;29(4):177-83. doi: 10.1016/j.jnci.2017.09.002.

20. Zheng HC, Gong BC. The roles of maspin expression in gastric cancer: a meta- and bioinformatics analysis. Oncotarget. 2017;8(39):66476-90. doi: 10.18632/oncotarget. 20192

21. Chim SS, Tong YK, Chiu RW, Lau TK, Leung TN, Chan LY, et al. Detection of the placental epigenetic signature of the maspin gene in maternal plasma. Proc Natl Acad Sci USA. 2005;102(41):14753-8. doi: 10.1073/pnas. 0503 335102.

22. Kaufmann P, Black S, Huppertz B. Endovascular trophoblast invasion: implications for the pathogenesis of intrauterine growth retardation and preeclampsia. Biol Reprod. 2003;69(1):1-7. doi: 10.1095/biolreprod.102.01 4977.

23. Sheridan R, Belludi C, Khoury J, Stanek J, Handwerger S. FOXO1 expression in villous trophoblast of preeclampsia and fetal growth restriction placentas. Histol Histopathol. 2015;30(2):213-22. doi: 10.14670/HH-30.213.

24. Huang X, Anderle P, Hostettler L, Baumann MU, Surbek DV, Ontsouka EC, et al. Identification of placental nutrient transporters associated with intrauterine growth restriction and pre-eclampsia. BMC Genomics. 2018;19(1):173. doi: 10.1186/s12864-018-4518-z

25. Goswami D, Tannetta DS, Magee LA, Fuchisawa A, Redman CW, Sargent IL, et al. Excess syncytiotrophoblast microparticle shedding is a feature of early-onset pre-eclampsia, but not normotensive intrauterine growth restriction. Placenta. 2006;27(1):56-61. doi: 10.1016/j. placenta.2004.11.007

26. Lorenzi T, Marzioni D, Giannubilo S, Quaranta A, 
Crescimanno C, De Luca A, et al. Expression patterns of two serine protease HtrA1 forms in human placentas complicated by preeclampsia with and without intrauterine growth restriction. Placenta. 2009;30(1):35-40. doi: 10.1016/j.placenta. 2008.10.016.

27. Chelbi ST, Wilson ML, Veillard AC, Ingles SA, Zhang J, Mondon F, et al. Genetic and epigenetic mechanisms collaborate to control SERPINA3 expression and its association with placental diseases. Hum Mol Genet. 2012;21(9): 1968-78. doi: 10.1093/hmg/dds006.
28. Chelbi ST, Mondon F, Jammes H, Buffat C, Mignot TM, Tost $\mathrm{J}$, et al. Expressional and epigenetic alterations of placental serine protease inhibitors: SERPINA3 is a potential marker of preeclampsia. Hypertension. 2007;49 (1):76-83. doi: 10.1161 /01.HYP.0000250831.52876.cb.

29. Auer J, Camoin L, Guillonneau F, Rigourd V, Chelbi ST, Leduc M, et al. Serum profile in preeclampsia and intrauterine growth restriction revealed by iTRAQ technology. J Proteomics. 2010;73(5):1004-17. doi:10.1016/j.jprot. 2009.12. 014. 